J. DeFaye. Bull. Soc. Chim. Fr. 2686 (1964).

8. S. R. SCHOV and T. C. MCMORrIS. J. Org. Chem. 44, 3760 (1979).
9. P. E. Sonnet. J. Org. Chem. 39, 3793 (1974),

10. B. M. Trost and D. P. Curran. Tetrahedron Lett. 22, 1287 (1981).

\title{
An exceptional 5-endo-trig reversal; a convergent synthesis of daunomycinone
}

\author{
B. A. KEAY \\ Department of Chemistry, University of Waterloo, Waterloo, Ont., Canada N2L $3 G 1$ \\ AND \\ R. RODRIGO' \\ Department of Chemistry, Wilfrid Laurier University, Waterloo, Ont. Canada N2L $3 C 5$ \\ Received Novenber 30, 1982
}

\begin{abstract}
B. A. KeAY and R. Rodrigo. Can. J. Chem. 61, 637 (1983).
A convergent $A B+C D$ route to daunomycinone (1) is described. The $A B$ segment is synthesized from the Diels $-A$ ider adduct (3) of an isobenzofuran and methyl vinyl ketone by means of an unusual 5 -endo-trig cleavage $(3 \rightarrow 4)$. The CD half (9) is combined with the $A B$ by the Kraus annelation technique to provide a 9-deoxy daunomycinone derivative $(\mathbf{1 2} a)$ which is subsequently oxygenated.
\end{abstract}

\section{B. A. Keay et R. Rodrigo. Can. J. Chem. 61, 637 (1983).}

Voici la description d'un tracé convergent $A B+C D$ vers le daunomycinone (1). Le segment $A B$ est synthétisé à partir de l'adduct Diels -Alder d'un isobenzofuranne et méthyl vinyl cétone à l'aide d'un clivage inhabituel 5-endo-trig $(\mathbf{3} \rightarrow \mathbf{4})$. La portion $\mathrm{CD}(\mathbf{9})$ est combinée à $\mathrm{AB}$ par la technique d'annellation Kraus afin de fournir un dérivé 9-déoxy daunomycinone (12a) qui est par la suite oxigéné.

[Traduit par le journal]

The glycoside daunomycine, an anthraquinone antibiotic of the anthracycline group, was isolated from Streptomyces species in 1963. The deluge of synthetic activity that followed the clinical trial and application of some of these antibiotics in cancer chemotherapy continues unabated and needs no recounting (for a comprehensive review, see ref. 1). Problems in anthracyclinone synthesis have been capably defined (2) and elegantly solved (3), particularly with respect to the aglycone daunomycinone $\mathbf{1}$. In this report we offer a synthesis of $\mathbf{1}$ incorporating regiocontrolled $A B+C D$ convergence and a new, efficient construction of the $A B$ segment.

Our method features the "isobenzofuran - Diels-Alder" techniques developed (4) in this laboratory for a one-step construction of the requisite carbon skeleton. Thus the known lactol 2, easily prepared from 2,3-dicyanohydroquinone (5) or 2,5-dimethoxybenzyl alcohol, ${ }^{2}$ reacts smoothly with methyl vinyl ketone under mild acid catalysis to provide the bridged Diels-Alder adduct 3 in $90 \%$ yield. This molecule contains all the desired carbon and oxygen atoms, barring the 9-hydroxyl group, of the $A B$ half of daunomycinone. The 7-hydroxyl group of the molecule, frequently a "difficult" function introduced later in many previous syntheses, develops from the oxygen atom of the isobenzofuran intermediate, the bridging oxygen atom of $\mathbf{3}$. It is realized by an unusual 5-endo-trig reversal, formally a retro-Michael reaction, triggered by treatment of $\mathbf{3}$ with methanolic methoxide ion. The reaction is a

\footnotetext{
'Author to whom correspondenee may be addressed.

${ }^{2} 2,5$-Dimethoxybenzyl alcohol was converted to its vinyl ether and lithiated (6). The lithiated species was reacted with dimethyl formamide and hydrolyzed to the lactol 2 .
}

remarkably smooth process $(90 \%$ of 4 ) yielding no other recognizable products, for a supposedly disfavoured pathway (7). We are investigating its mechanism but so far have failed to obtain any firm data to support an alternative rationalization. Sodium amalgam reduction of the enone $(95 \%)$ and protection of the benzyl alcohol as a tert-butyl dimethylsilyl ether $(90 \%)$ were unexceptional steps which provided $\mathbf{5}$, our $A B$ synthon lacking only the C-9 tertiary hydroxyl group of $\mathbf{1}$. The addition-cyclization technique developed by Kraus and Sugimoto (8) for anthraquinone synthesis offered the best hope for regiocontrolled production of daunomycinone from $\mathbf{5}$, but in subsequent applications of the Kraus method yields were reported (9) to be only moderate when acidic hydrogen atoms or carbonyl functions were present in the enone component. In accordance with these considerations, $\mathbf{5}$ was reduced with DIBAL-H (90\%) and subjected to anodic oxidation (10). The resulting benzoquinone ketal 6 produced in $90 \%$ yield was hydrolysed with a pH 5 acetate buffer to provide a $4: 1$ mixture $^{3}$ of monoketals $7 a$ and $7 b$ (total $86 \%$ ) which were separated by flash chromatography but are more conveniently carried through as a mixture for separation at a more opportune stage later on. The mix ture was silylated (90\%) to provide $8 a$ and $\mathbf{8} b$, and was now ready for the Kraus annelation.

The cyanophthalide 9 , our CD segment, was easily prepared in three steps from $m$-anisaldehyde. The latter was converted into its dimethyl acetal, regiospecifically deprotonated (1I), and quenched with carbon dioxide. Treatment of the resulting

\footnotetext{
${ }^{3}$ This was a disappointing result in view of the $>95 \%$ regioselectivity obtained previously in the hydrolysis of a similar bis-ketal (Swenton and co-workers (9)).
} 
<smiles>COc1cccc(C=O)c1CO</smiles>

9<smiles>COc1ccc(OC)c2c1C1CC(C)C2c2c(C)cccc21</smiles>

3<smiles>COc1ccc(OC)c2c1C=C(C)CC2O</smiles>

4<smiles>COc1ccc(OC)c2c1CC(C)C[C@H]2OC</smiles>

5

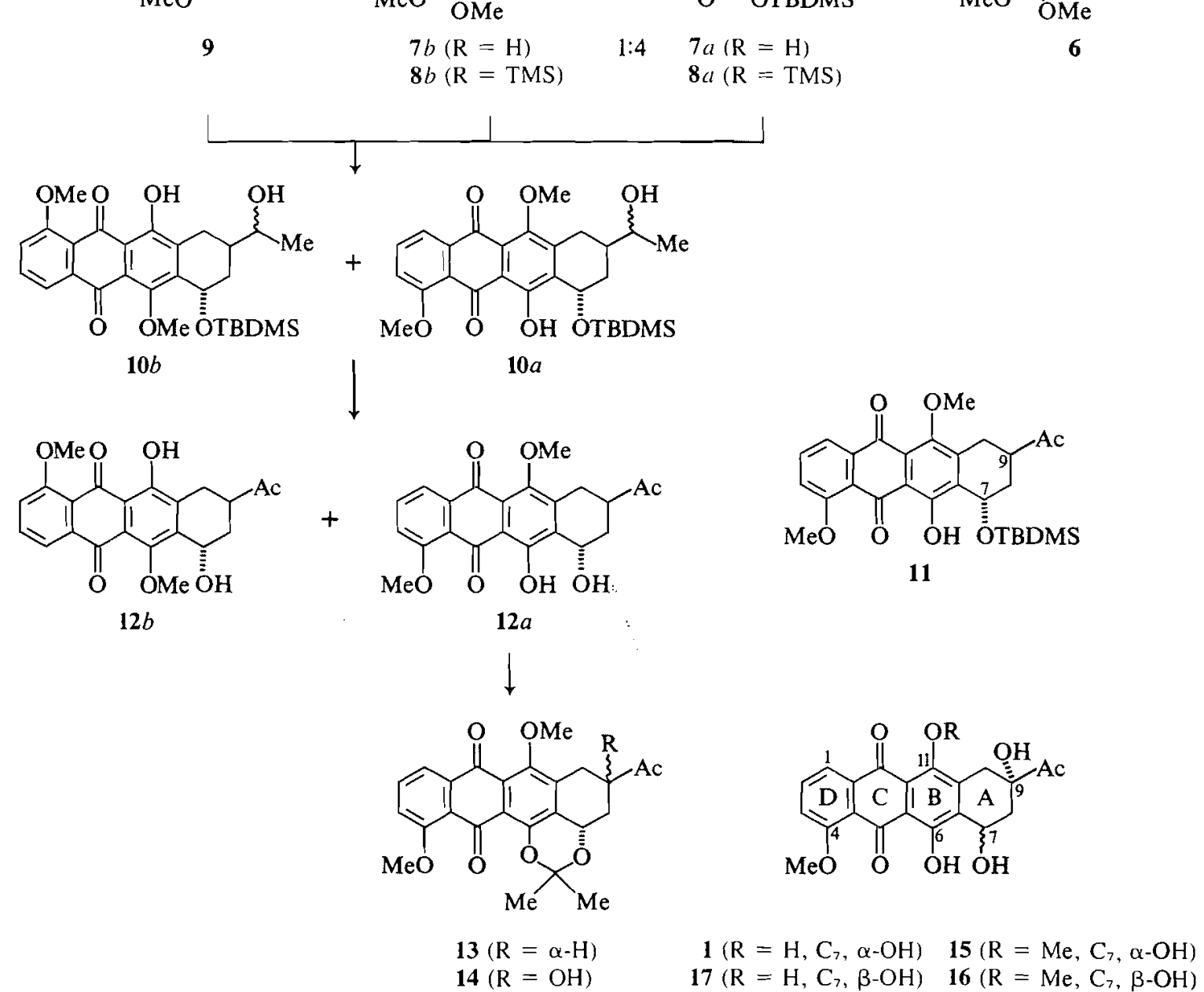

SCHEME 1. The synthesis of daunomycinone (1).

lactol with potassium cyanide and acetic acid provided the cyanohydrin which cyclized to 9 upon crystallization. Deprotonation of 9 with LDA/HMPA, followed by treatment with the monoketal mixture $(\mathbf{8} a+\mathbf{8} b)$ and work-up with $20 \%$ aqueous acetic acid, provided an excellent yield $(87 \%)$ of anthraquinones $10 a+10 b$. Reoxidation of the free alcohol proceeded efficiently $(85 \%, 11)$ with PDC in DMF and this was followed by removal $(93 \%)$ of the silyl protecting group with acid. Therefore the entire $\mathrm{AB}+\mathrm{CD}$ attachment sequence $(\mathbf{5} \rightarrow$ $12 a+b$ ) proceeded in an excellent overall yield of $40 \%$ (seven steps). The slight structural differences that exist between regioisomers $12 a$ and $12 b$ can now be profitably exploited. In particular the peri-dihydroxy system at C-6,C-7 in $12 a$ was converted to an acetonide (13, 80\%) by 2-methoxy propene $/ p$-toluene sulfonic acid treatment of the mixture in dry methylene chloride; $12 b$, which cannot form such an acetonide, is then easily separated from $12 a$ by chromatography.

The ' $\mathrm{H} \mathrm{nmr}$ spectra of $5(80 \mathrm{MHz}), \mathbf{1 1}$, and $13(400 \mathrm{MHz})$ were examined with and without $\mathrm{H}-7$ decoupling to establish the $\mathrm{C}-7, \mathrm{C}-9$ relative configurations shown for these intermediates. All $J$ values for protons at C-8, C-9, and C-10 in $\mathbf{1 1}$ and 13 were measured and the results in 11 found to be virtually identical with published values ${ }^{4}$ for 9-deoxydaunomycinone. Oxygenation of the acetonide 13 was accomplished re-

${ }^{4}$ Reference 1, p. 179. 
producibly in $85 \%$ yield by a modified Gardner procedure (12) to produce a $2: 3$ diastereomeric mixture of 9-hydroxy ketones 14 , and followed by brief acid hydrolysis to remove the protecting isopropylidene group. Column chromatography provided the individual diols $\mathbf{1 5}$ and $\mathbf{1 6}$ in the same ratio. Ring A coupling constants measured from the $400 \mathrm{MHz}$ spectra of 15 and 16 correlate well with those reported (13) for isodaunomycinone and isoepidaunomycinone respectively. Boron trichloride demethylation at $-78^{\circ} \mathrm{C}$ was selective for the $\mathrm{C}-11$ methoxyl group in both cases and subsequent work-up with aqueous bicarbonate provided daunomycinone 1 (from 15) and epidaunomycinone 17 (from 16). Again, a $400 \mathrm{MHz}$ spectrum of our synthetic product had all chemical shifts and coupling constants identical with those published (14) for daunomycinone. Since epidaunomycinone $\mathbf{1 7}$ has been previously isomerized (15) to daunomycinone, this concludes our synthesis ${ }^{5}$ in fourteen steps and ca. $14 \%$ yield from 2 .

\section{Acknowledgements}

We thank the Natural Sciences and Engineering Research Council of Canada for financial support. The $400 \mathrm{MHz}$ spectra were obtained at the South-Western Ontario NMR Centre funded by a major installation grant from NSERC Canada.

I. F. ARCAMONE. Doxorubicin anticancer antibiotics. In Medicinal chemistry. Vol. 17. Academic Press, New York. 1981.

2. T. R. Kelly. Ann. Rep. Med. Chem. 14, 288 (1979).

3. T, R. Kelly, J. Vaya, and L. Ananthasubramaniam. J. Am.

${ }^{5}$ Full details will be published later. All new compounds provided analytical and/or spectroscopic data entirely consistent with their structures.
Kimball, D. R. Walt, and F. Johnson. J. Am. Chem. Soc. 103, 156l (1981); J. P. Gesson and M. MONDON. Chem. Conmun. 421 (1982); M. J. BROADHURST, C. H. HASSAL, and G. J. Thomas. Chem. Commun. 158 (1982); J. Chem. Soc. Perkin Trans. 1. 2227 (1982); 2239 (1982); 2249 (1982); Y. TAMURA, A. Wada, M. Sasho, K. Fukunaga, H. Maeda, and Y. Kita. J. Org. Chem. 47, 4376 (1982); H. SeKIZAKI, M. Jung, J. M. MCNAMARA, and Y. KISHI. J. Am. Chem. Soc. 104, 7372 (1982).

4. B. A. KEAY, D. K. W. LEE, and R. RODRIGO. Tetrahedron Lett. 3363 (1980); B. A. KeAY and R. Rodrigo. J. Am. Chem. Soc. 104, 4725 (1982), and ref. 6 therein; B. A. KEAY and R. Rodrigo. Can. J. Chem. In press.

5. C. D. Perchonock and B. LoEv. Prostaglandins, 15, 623 (1978).

6. R. C. Ronald, J. M. Lansinger, T, S. Lillie, and C. J. WheEler. J. Org. Chem. 47, 2541 (1982).

7. J. E. BALDWIN and L. I. KRUSE. Chem. Commun. 233 (1977); J. E. Baldwin, J. Cutting, W. Dupont, L. Kruse, L. Silberman, and R. C. ThOMAs. Chem. Commun. 736 (1976).

8. G. A. Kraus and H. Sugimoto. Tetrahedron Lett. 2263 (1978).

9. T. LI and Y. L. WU. J. Am. Chem. Soc. 103, 7007 (1981); M. G. Dolson, B. L. Chenard, and J. S. Swenton. J. Am. Chem. Soc. 103, 5263 (I981).

10. D. R. Henton, R. L. McCreery, and J. S. Swenton. J. Org. Chem. 45, 369 (1980).

11. H. P. Plauman, B. A. Keay, and R. Rodrigo. Tetrahedron Lett. 4921 ( 1979 ).

12. J. N. Gardner, F. E. Carlon, and D. Gnoj. J. Org. Chem. 33, 3294 (1968)

13. K. KROHN and K. TOlKIEHN. Chem. Ber. 112, 3453 (1979).

14. T. H. Smith, A. N. Fujiwara, W. W. LeE, H. Y. Wu, and D. W. HenRy, J. Org. Chem. 42, 3653 (1977).

15. A. S. Kende, Y. TSAY, and J. E. Mills. J. Am. Chem. Soc. 98, 1967 (1976).

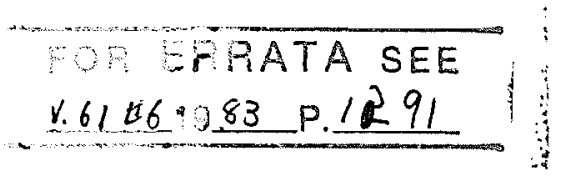

